\title{
Gastric Adenomatous Polyp
}

National Cancer Institute

\section{Source}

National Cancer Institute. Gastric Adenomatous Polyp. NCI Thesaurus. Code C95773.

A neoplastic polyp that arises from the stomach. It is usually associated with intestinaltype differentiation. The presence of high grade dysplasia and a size of more than $2 \mathrm{~cm}$ are factors that increase the risk of malignant transformation. 